\title{
Clinical Characteristics and Therapeutic Adherence of Women in a Referral Outpatient Clinic for Severe Hypertension
}

Pedro Henrique Barletta, ${ }^{1 \oplus}$ Eduardo Faria Soares de Magalhães, ${ }^{1 \oplus}$ Vitor Fernandes de Almeida, ${ }^{1}$ Júlia Lasserre

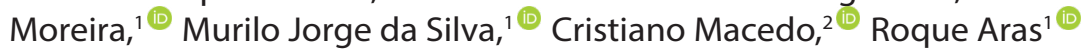

Faculdade de Medicina da Bahia da Universidade Federal da Bahia, ${ }^{2}$ Salvador, BA - Brazil

Hospital Universitário Professor Edgard Santos, ${ }^{2}$ Salvador, BA - Brazil

\section{Abstract}

Background: Cardiovascular disease is the main cause of death worldwide. There is a lack of studies addressing this issue in women and its risk factors, such as hypertension.

Objective: To evaluate the clinical and therapeutic profile of women with hypertension and to determine which factors are related to treatment adherence and blood pressure control.

Methods: Cross-sectional study of 181 hypertensive women treated at an outpatient referral clinic. Data were obtained from medical records, face-to-face interviews, and physical examination, using a standardized form. Statistical analysis was performed with prevalence ratio, chi-square and Student's $t$ test. Significance was accepted at $\mathrm{p}<0.05$.

Results: Most patients were mixed-race or black $(91.7 \%)$ and the mean age was 66.09 years. Only $44.2 \%$ of patients had controlled blood pressure. The prevalence of stroke was $14.9 \%$, whereas the prevalence of coronary artery disease was $19.3 \%$. The mean number of oral antihypertensive drugs prescribed to each individual was 3.41. A history of stroke was more often found in patients with uncontrolled blood pressure ( $p=0.013$ ) and in those using three or more antihypertensives $(\mathrm{p}=0.023)$. Eighty patients $(44.2 \%)$ had high treatment adherence. Depression was more frequently reported by patients with poorer adherence to treatment $(\mathrm{p}=0.026)$.

Conclusion: Women with hypertension presented a high prevalence of cardiovascular risk factors and cardiovascular events, including a significantly higher prevalence of stroke in those with uncontrolled hypertension. Self-reported depression may help identify patients at risk of nonadherence to treatment.

Keywords: Women; Hypertension; Medication Adherence; Antihypertensive Agents; Blood Pressure.

\section{Introduction}

Cardiovascular disease (CVD) is the leading cause of death worldwide. For many years, it was believed that CVD was much more prevalent in men, probably due to the lack of studies that addressed this issue in women and their risk factors, according to their biological particularities. ${ }^{1}$ Cardiovascular risk factors common to both genders have been identified. However, some studies have shown that these factors are associated with worse outcomes in women in comparison to men. ${ }^{2-4}$ In general, women usually develop CVD 10 years later than men, so that the prevalence of CVD increases in the postmenopausal period, probably due to the decline in estrogen hormone levels. ${ }^{5}$

There is little difference in the prevalence of arterial hypertension between genders, but previous studies have shown that women tend to receive less aggressive

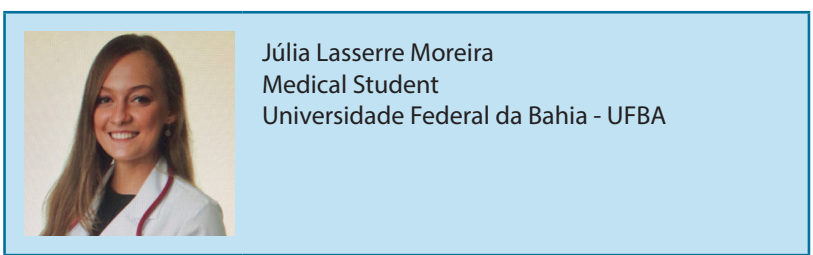


antihypertensive treatment than men. ${ }^{6}$ This finding may be related to therapeutic inertia in the approach to women or poor adherence to antihypertensive treatment, which may lead to increased cardiovascular morbidity and mortality. ${ }^{7}$

Despite knowledge about gender differences in arterial hypertension management and prevalence of CVD, these relations are still insufficiently understood, especially in the Brazilian population. Given the lack of studies focused on the clinical management of arterial hypertension in women, our objective was to evaluate the clinical and therapeutic profile of women followed at a referral outpatient clinic for arterial hypertension and to determine which factors were associated with treatment adherence and blood pressure control.

\section{Methods}

This was a descriptive, cross-sectional study carried out in an outpatient referral clinic for Severe Hypertensive Cardiovascular Disease at a university hospital in the city of Salvador, Bahia. The study included a convenience sample of female patients with a previous diagnosis of hypertension, aged 18 years or older, followed at the aforementioned clinic, between June 2018 and February 2020. Patients unable to respond to the questionnaire were excluded.

Information was obtained by trained raters through face-to-face interviews, physical examination, and a review of medical records. A standard form approved by the institution's Research Ethics Committee was used. All patients agreed to participate in the study and signed a free and informed consent form.

Patients were referred to a treatment room, where they were asked to remain seated and answered questions on their life habits, medical history, therapeutic scheme used, and adherence to the proposed treatment. After a few minutes, blood pressure was measured using a digital sphygmomanometer (BP785, Omron Healthcare). The patients were instructed to sit with their backs against the chair, feet uncrossed and on the floor. They were also instructed to empty their bladder before the measurement. There was a minimum interval of 30 minutes between the intake of caffeinated beverages and smoking and the measurement, as well as 60 minutes between physical exercise and blood pressure measurement.
The arm was positioned extended, at the height of the heart, and after palpation of the brachial artery, the cuff was positioned 3 centimeters above the cubital fossa. For obese patients, a suitable cuff with a larger circumference was used (HEMCL24, Omron Healthcare). The measurement was performed in both arms, with an interval of at least 1 minute between measurements. Of these two measurements, the one with the highest mean arterial pressure $[(2 \mathrm{x}$ diastolic blood pressure + systolic blood pressure) / 3] was considered for the analysis.

Patients with uncontrolled blood pressure (BP) despite the use of $\geq 3$ antihypertensive drugs with synergistic actions, at maximum recommended or tolerated doses, or those with BP controlled only with $\geq 4$ antihypertensive drugs were considered to have apparent resistant hypertension (RH). ${ }^{8}$ Uncontrolled hypertension was defined as a systolic blood pressure $\geq 140 \mathrm{mmHg}$ or diastolic blood pressure $\geq 90 \mathrm{mmHg}{ }^{8}$

To assess medication adherence, the 8-item Morisky Medication Adherence Scale (MMAS-8) was used. Individuals with scores of 8, $7-6$ and $\leq 5$ were classified as having high, moderate, and low therapeutic adherence, respectively. Patients who had high adherence were considered adherent to treatment, while patients with moderate and low adherence were classified as nonadherent.

Information about the pharmacological prescriptions of each individual was obtained from medical records. Serum potassium $\left(\mathrm{K}^{+}\right)$and serum creatinine $(\mathrm{Cr})$ levels were also obtained from medical records, to search for a possible rationale for not using drugs known to induce hyperkalemia. The presence of previous cardiovascular events (such as stroke and acute myocardial infarction) or comorbidities (heart failure, coronary artery disease, diabetes, dyslipidemia) was defined by a positive history reported by the participant and/or noted in the medical record.

The glomerular filtration rate (GFR) was estimated using the Chronic Kidney Disease Epidemiology Collaboration group (CKD-EPI) equation. ${ }^{9}$ Renal function was considered abnormal when GFR $<60 \mathrm{~mL} / \mathrm{min}$. Obesity was defined as a body mass index (BMI) greater than $30 \mathrm{~kg} / \mathrm{m}^{2}$.

Depression was defined by a self-reported previous medical diagnosis of major depression in need of pharmacological antidepressant therapy. Sedentary lifestyle was defined as self-reported physical inactivity 
or less than 150 minutes of physical activity per week. Difficulty in replacing medications, alcohol use, and smoking were all based on self-report.

\section{Statistical Analysis}

Statistical analysis was performed in SPSS, Version 23.0. Categorical variables were presented as absolute and relative frequencies, while continuous variables were presented as means and standard deviations (SD). The relative frequencies were presented as valid percentages. The chi-square $\left(\chi^{2}\right)$ statistic and prevalence ratio (PR) were used to investigate associations. The Kolmogorov-Smirnov test was used to certify the normality of the data distribution. The comparison of means was performed using Student's $t$ test for independent samples. The mean blood pressure values obtained were compared with the target blood pressure levels of $140 / 90 \mathrm{mmHg}$ using the one-sample $t$ test. Statistical significance was established at $\mathrm{p}<0.05$, two-tailed.

\section{Ethical Considerations}

This study was approved by the Research Ethics Committee of Hospital Universitário Professor Edgard Santos, Universidade Federal da Bahia, on April 25, 2018. In accordance with Brazilian National Health Council Resolution No. 466/2012 on research involving human beings, the study protocol was registered on the Plataforma Brasil website (CAAE number 81701717.6.0000.0049). All authors signed a data use agreement. The standardized form used to collect patient information was approved by the local institutional review board.

\section{Results}

The sample consisted of 181 patients. Of these, 103 $(57.5 \%)$ self-identified as black, $63(35.2 \%)$ as mixedrace, and $10(5.6 \%)$ as white. The mean age of patients was 66.09 years $( \pm 10.44)$, with a minimum age of 39 and maximum of 87 years. The mean systolic blood pressure (SBP) was $146.93( \pm 25.67) \mathrm{mmHg}(\mathrm{p}<0.001)$. The mean diastolic blood pressure (DBP) was $83.09( \pm 13.45) \mathrm{mmHg}$ $(p<0.001)$. Table 1 presents the main comorbidities of the patients.

Only $44.2 \%$ of patients had controlled blood pressure. One hundred and ten $(60.8 \%)$ were considered to have apparent RH. Regarding therapeutic adherence, the mean score on the MMAS- 8 scale was $6.85( \pm 1.52)$ points, and the percentage of individuals with low therapeutic adherence was $13.8 \%$; moderate adherence, $42.0 \%$; and high adherence, $44.2 \%$.

Table 1 presents the PR values of the independent variables in relation to blood pressure control. A history of stroke was more often found in patients with uncontrolled $\mathrm{BP}(\mathrm{p}=0.013)$, who also took more antihypertensive drugs in comparison to patients with controlled $B P(p=0.023)$. There was no statistical difference in the mean score on the MMAS-8 scale between patients with and without a previous stroke (6.67 vs 6.88, $\mathrm{p}=0.509$ ), and no difference in adherence was noted between the group of individuals using 3 or more drugs and the group using fewer than 3 drugs (6.87 vs 6.75, $\mathrm{p}=0.654$ ).

Regarding the medication profile (Table 2), the mean number of oral antihypertensive drugs taken by each individual was 3.41 ( \pm 1.20$)$. Antihypertensive monotherapy was prescribed only to $2.2 \%$ of patients; $19.9 \%$ were taking two antihypertensive drugs; $35.4 \%$ were taking three drugs, whereas the remaining $42.5 \%$ of the patients were on four or more drugs. Twenty-four patients (13.3\%) had uncontrolled blood pressure despite use of five or more antihypertensive drugs.

Considering only those patients with apparent $\mathrm{RH}$, $71.56 \%$ of these individuals were on a therapeutic regimen consisting of an angiotensin-converting enzyme inhibitor (ACEI) or angiotensin II receptor blocker (ARB) + diuretic + calcium channel blocker (CCB). Among these individuals, considering those who needed 4 or more antihypertensive drugs, a beta-blocker was the most commonly prescribed fourth drug (63.6\%), whereas $58.2 \%$ of the patients took spironolactone. In this same group of patients, the mean $\left[\mathrm{K}^{+}\right]$of those who did not take spironolactone was $4.13( \pm 0.55)$ $\mathrm{mmol} / \mathrm{L}$, versus $4.51( \pm 0.39) \mathrm{mmol} / \mathrm{L}$ in those who did, a statistically significant difference $(p=0.028)$. The mean serum creatinine level among those who did not take spironolactone and those who did was, respectively, $0.92( \pm 0.20) \mathrm{mg} / \mathrm{dL}$ and $0.90( \pm 0.24) \mathrm{mg} / \mathrm{dL}$, with no significant difference $(\mathrm{p}=0.857)$.

Patients who were on four or more antihypertensive drugs had a higher prevalence of coronary artery disease (CAD) $(27.3 \%$ vs $13.5 \%$, $\mathrm{p}=0.020)$, previous myocardial infarction (MI) (20.8\% vs 9.6, $\mathrm{p}=0.034)$, and heart failure (HF) $(19.7 \%$ vs $8.7 \%, \mathrm{p}=0.033)$ in comparison to those who took three or fewer antihypertensives.

Of the patients with uncontrolled blood pressure despite the use of 5 or more antihypertensive drugs, 
Table 1 - Variables in relation to blood pressure control

\begin{tabular}{|c|c|c|c|c|c|c|}
\hline \multirow{2}{*}{ Variable } & \multirow{2}{*}{$\begin{array}{l}\text { Regarding to the } \\
\text { total sample }\end{array}$} & \multirow{2}{*}{$\begin{array}{c}\text { Controlled BP } \\
\qquad(n=79)\end{array}$} & \multirow{2}{*}{$\begin{array}{c}\text { Uncontrolled BP } \\
\qquad(\mathrm{n}=101)\end{array}$} & \multirow{2}{*}{ PR } & \multirow{2}{*}{$\begin{array}{l}95 \% \\
\text { confidence } \\
\text { interval }\end{array}$} & \multirow{2}{*}{ p-value } \\
\hline & & & & & & \\
\hline Age (years) & $66.09( \pm 10.44)$ & $64.83( \pm 10.09)$ & $67.10( \pm 10.66)$ & - & - & 0.146 \\
\hline Number of drugs used & $3.41( \pm 1.20)$ & $3.09( \pm 1.12)$ & $3.66( \pm 1.20)$ & - & - & 0.001 \\
\hline $\mathrm{SBP}(\mathrm{mmHg})$ & $146.93( \pm 25.67)$ & $125.61( \pm 11.34)$ & $163.81( \pm 20.80)$ & - & - & $<0.001$ \\
\hline DBP (mmHg) & $83.09( \pm 13.45)$ & $76.26( \pm 8.83)$ & $88.50( \pm 14.03)$ & - & - & $<0.001$ \\
\hline $\begin{array}{l}\text { Years of follow-up at the } \\
\text { clinic }\end{array}$ & $15.12( \pm 8.89)$ & $15.50( \pm 9.90)$ & $14.82( \pm 8.06)$ & - & - & 0.612 \\
\hline Years of schooling & $7.93( \pm 4.17)$ & $8.15( \pm 3.90)$ & $7.75( \pm 4.38)$ & - & - & 0.526 \\
\hline $\begin{array}{l}\text { Years since diagnosis of } \\
\text { hypertension }\end{array}$ & $24.50( \pm 11.40)$ & $23.84( \pm 11.84)$ & $25.05( \pm 11.07)$ & - & - & 0.486 \\
\hline African descent & $166(91.7 \%)$ & $73(91.3 \%)$ & $93(92.1 \%)$ & 0.942 & $0.534-1.662$ & 0.841 \\
\hline Obesity (BMI > $30 \mathrm{~kg} / \mathrm{m}^{2}$ ) & $73(41.7 \%)$ & $36(45.6 \%)$ & $37(38.5 \%)$ & 1.170 & $0.845-1.619$ & 0.348 \\
\hline Sedentary lifestyle & $85(47.0 \%)$ & $39(48.8 \%)$ & $46(45.5 \%)$ & 1.074 & $0.775-1.490$ & 0.668 \\
\hline $\begin{array}{l}\text { Difficulty in replacing } \\
\text { medications }\end{array}$ & $31(23.8 \%)$ & $16(28.1 \%)$ & $15(20.5 \%)$ & 1.246 & $0.824-1.885$ & 0.318 \\
\hline Alcoholism & $38(21 \%)$ & $20(25.0 \%)$ & $18(17.8 \%)$ & 1.254 & $0.877-1.794$ & 0.239 \\
\hline Current smoking & $6(3.3 \%)$ & $4(5.0 \%)$ & $2(2.0 \%)$ & 1.535 & $0.850-2.771$ & 0.260 \\
\hline $\begin{array}{l}\text { On three or more } \\
\text { antihypertensives }\end{array}$ & $141(77.9 \%)$ & $56(70.0 \%)$ & $85(84.2 \%)$ & 0.662 & $0.478-0.916$ & 0.023 \\
\hline $\mathrm{HF}$ & $24(13.4 \%)$ & $15(18.8 \%)$ & $9(9.1 \%)$ & 1.490 & $1.039-2.138$ & 0.059 \\
\hline CAD & $35(19.3 \%)$ & $13(16.3 \%)$ & $20(21.8 \%)$ & 0.809 & $0.508-1.289$ & 0.349 \\
\hline CKD & $27(17.8 \%)$ & $11(15.7 \%)$ & $16(19.5 \%)$ & 0.863 & $0.528-1.411$ & 0.541 \\
\hline Diabetes & $87(48.1 \%)$ & $36(45.0 \%)$ & $51(50.5 \%)$ & 0.884 & $0.635-1.230$ & 0.462 \\
\hline Dyslipidemia & $139(77.7 \%)$ & $65(82.3 \%)$ & $74(74.0 \%)$ & 1.336 & $0.845-2.112$ & 0.187 \\
\hline Stroke & $27(14.9 \%)$ & $6(7.5 \%)$ & $21(20.8 \%)$ & 0.462 & $0.224-0.954$ & 0.013 \\
\hline Self-reported depression & $41(22.8 \%)$ & $18(22.8 \%)$ & $23(22.8 \%)$ & 1.000 & $0.675-1.483$ & 0.998 \\
\hline $\begin{array}{l}\text { Categorical variables were } \\
\text { Continuous variables were } \\
\text { BP: blood pressure; CAD: } \\
\text { systolic blood pressure; DBI }\end{array}$ & $\begin{array}{l}\text { ented as n (valid \%) } \\
\text { ented as mean }( \pm S L \\
\text { ry artery disease; } H \\
\text { stolic blood pressure }\end{array}$ & $\begin{array}{l}\text { ne p-values were ob } \\
\text { the p-values were } \\
\text { t failure; BMI: bod }\end{array}$ & $\begin{array}{l}\text { from the chi-square } \\
\text { drom the Student' } \\
\text { index; CKD: chron }\end{array}$ & y dise & PR: prevalence 1 & SBP: \\
\hline
\end{tabular}

20.8\% did not take spironolactone, and 54.2\% did not take the combination of chlortalidone and spironolactone.

Table 3 shows the PR values of the independent variables and the comparison of the means of the continuous variables in relation to treatment adherence. Comparing the treatment-adherent group (MMAS-8 = 8) to the nonadherent group (MMAS-8 $\leq 7$ ) revealed that depression was more frequently reported by patients with poorer adherence to treatment $(\mathrm{p}=0.026)$. There was no statistically significant difference in mean age, number of drugs taken, or mean pressure levels. There was no significant impact of number of years of follow-up at the clinic, education level, and time since diagnosis of hypertension. There was no association between high therapeutic adherence and blood pressure control ( $p=0.653)$. 
Table 2 - Antihypertensive drugs and percentage of use in the sample

\begin{tabular}{|c|c|c|c|}
\hline \multirow{2}{*}{ Drugs } & $\begin{array}{l}\text { Percentage of individuals } \\
\text { using the drug }\end{array}$ & HTN & Apparent RH \\
\hline & $(\mathrm{N}=181)$ & $(\mathrm{N}=71)$ & $(\mathrm{N}=110)$ \\
\hline Thiazide diuretics & $81.2 \%$ & $73.3 \%$ & $86.4 \%$ \\
\hline Hydrochlorothiazide & $54.1 \%$ & $59.2 \%$ & $50.9 \%$ \\
\hline Chlortalidone & $25.4 \%$ & $11.3 \%$ & $34.5 \%$ \\
\hline Indapamide & $1.7 \%$ & $2.8 \%$ & $0.9 \%$ \\
\hline \multicolumn{4}{|l|}{ Other diuretics } \\
\hline Spironolactone & $28.2 \%$ & $1.4 \%$ & $45.5 \%$ \\
\hline Furosemide & $6.6 \%$ & $1.4 \%$ & $10.0 \%$ \\
\hline ACEI/ARB & $98.9 \%$ & $98.6 \%$ & $99.1 \%$ \\
\hline Losartan & $70.7 \%$ & $71.8 \%$ & $70.0 \%$ \\
\hline Enalapril & $23.2 \%$ & $22.5 \%$ & $23.6 \%$ \\
\hline Captopril & $0.6 \%$ & $1.4 \%$ & $0.0 \%$ \\
\hline ССВ & $70.2 \%$ & $52.1 \%$ & $81.8 \%$ \\
\hline Amlodipine & $68 \%$ & $50.7 \%$ & $79.1 \%$ \\
\hline Nifedipine & $2.2 \%$ & $1.4 \%$ & $2.7 \%$ \\
\hline Beta-blocker & $36.5 \%$ & $11.3 \%$ & $52.7 \%$ \\
\hline Carvedilol & $18.8 \%$ & $1.4 \%$ & $30.0 \%$ \\
\hline Atenolol & $11.0 \%$ & $5.6 \%$ & $14.5 \%$ \\
\hline Propranolol & $3.9 \%$ & $1.4 \%$ & $5.5 \%$ \\
\hline Metoprolol & $3.3 \%$ & $2.8 \%$ & $3.6 \%$ \\
\hline Direct vasodilators & $5.5 \%$ & $0.0 \%$ & $9.1 \%$ \\
\hline Central alpha-agonists & $10.5 \%$ & $0.0 \%$ & $17.3 \%$ \\
\hline
\end{tabular}

\section{Discussion}

This study analyzed the clinical characteristics of 181 female hypertensive patients followed at an outpatient referral clinic for severe hypertension. We observed a high prevalence of concomitant risk factors for CVD, including dyslipidemia (78\%), diabetes mellitus $(48 \%)$, and obesity $(42 \%)$, as previously described in patients with $\mathrm{RH} .{ }^{10}$ However, we found a lower prevalence of current smoking (3\%), probably reflecting sex differences in the prevalence of traditional cardiovascular risk factors..$^{11}$ In a previous study involving hypertensive patients followed in primary health care centers in Portugal (the PRECISE study), the prevalence of cardiovascular comorbidities in women was similar to that found in our sample, especially for dyslipidemia, current smoking, and obesity, in addition to similar rates of uncontrolled hypertension..$^{12}$ Thus, the frequency of cardiovascular comorbidities in our sample was similar to that described in other countries.

Considering cardiovascular events, we found a significantly higher prevalence of stroke in patients with uncontrolled hypertension, who also took more antihypertensive drugs in comparison to patients 
Table 3 - Variables of interest and relation to therapeutic adherence

\begin{tabular}{|c|c|c|c|c|c|}
\hline \multirow{2}{*}{ Variable } & Adherent & Nonadherent & \multirow{2}{*}{ PR } & \multirow{2}{*}{$\begin{array}{l}95 \% \text { confidence } \\
\text { interval }\end{array}$} & \multirow{2}{*}{ p-value } \\
\hline & $(n=80)$ & $(\mathrm{n}=101)$ & & & \\
\hline Age (years) & $67.03( \pm 8.97)$ & $65.36( \pm 11.47)$ & - & - & 0.274 \\
\hline Number of drugs used & $3.31( \pm 1.12)$ & $3.49( \pm 1.25)$ & - & - & 0.336 \\
\hline $\mathrm{SBP}(\mathrm{mmHg})$ & $146.33( \pm 25.35)$ & $147.40( \pm 26.03)$ & - & - & 0.782 \\
\hline $\mathrm{DBP}(\mathrm{mmHg})$ & $82.60( \pm 12.20)$ & $83.48( \pm 14.40)$ & - & - & 0.665 \\
\hline Years of follow-up at the clinic & $14.99( \pm 8.78)$ & $15.21( \pm 9.02)$ & - & - & 0.872 \\
\hline Years of schooling & $7.65( \pm 3.95)$ & $8.15( \pm 4.34)$ & - & - & 0.426 \\
\hline $\begin{array}{l}\text { Years since diagnosis of } \\
\text { hypertension }\end{array}$ & $22.88( \pm 10.00)$ & $25.85( \pm 12.33)$ & - & - & 0.085 \\
\hline African descent & $75(93.8 \%)$ & $91(90.1 \%)$ & 1.355 & $0.650-2.827$ & 0.376 \\
\hline Self-reported depression & $12(15.0 \%)$ & $29(29.0 \%)$ & 0.598 & $0.361-0.992$ & 0.026 \\
\hline $\mathrm{HF}$ & $8(10.3 \%)$ & $16(15.8 \%)$ & 0.738 & $0.408-1.334$ & 0.277 \\
\hline CAD & $15(18.8 \%)$ & $20(19.8 \%)$ & 0.963 & $0.630-1470$ & 0.859 \\
\hline Obesity (BMI > 30 kg/m2) & $38(48.7 \%)$ & $35(36.1 \%)$ & 1.327 & $0.957-1.841$ & 0.092 \\
\hline CKD & $16(23.5 \%)$ & $11(13.1 \%)$ & 1.425 & $0.979-2.074$ & 0.094 \\
\hline Difficulty in replacing medications & $10(16.9 \%)$ & $21(29.6 \%)$ & 0.652 & $0.377-1.127$ & 0.093 \\
\hline Alcoholism & $15(18.8 \%)$ & $23(22.8 \%)$ & 0.868 & $0.563-1.339$ & 0.509 \\
\hline Diabetes & $41(51.2 \%)$ & $46(45.5 \%)$ & 1.136 & $0.819-1.576$ & 0.445 \\
\hline Dyslipidemia & $62(79.5 \%)$ & $77(76.2 \%)$ & 1.115 & $0.731-1.701$ & 0.605 \\
\hline Stroke & $11(13.8 \%)$ & $16(15.8 \%)$ & 0.909 & $0.558-1.481$ & 0.695 \\
\hline Controlled BP & $37(46.3 \%)$ & $43(42.6 \%)$ & 1.086 & $0.783-1.507$ & 0.621 \\
\hline \multicolumn{6}{|c|}{$\begin{array}{l}\text { Categorical variables were represented as } n \text { (valid \%) and the p-values were obtained from the chi-square test; } \\
\text { Continuous variables were represented as mean }( \pm S D) \text { and the p-values were obtained from the Student's test; } \\
\text { Patients with } 8 \text { points on the MMAS- } 8 \text { scale were classified as adherent, whereas those scoring } 7 \text { points or less were classified as nonadherent. } \\
\text { CAD: coronary artery disease; HF: heart failure; BMI: body mass index; CKD: chronic kidney disease; PR: prevalence ratio; SBP: systolic blood pressure; } \\
\text { DBP: diastolic blood pressure; BP: blood pressure. }\end{array}$} \\
\hline
\end{tabular}

with controlled BP. Notably, the frequency of other cardiovascular risk factors was similar in the two subgroups, suggesting that inadequate BP control, probably more than other risk factors, plays a pivotal role in the development of stroke in patients with hypertension.

According to the literature, poor drug adherence is a major cause of uncontrolled hypertension and may lead to pseudo-resistance. ${ }^{13}$ In the present study, $44.2 \%$ of patients were considered highly adherent to antihypertensive treatment, whereas $13.8 \%$ had low adherence based on the MMAS- 8 questionnaire. Oliveira-Filho et al $^{14}$ reported a much lower proportion of high adherence (19.7\%) in 223 patients followed at primary care units, and Morisky et al ${ }^{15}$ found that only $15.9 \%$ of patients followed at a hypertension clinic had high therapeutic adherence. The higher prevalence of adherence observed in our study could be explained, at least in part, by the fact that the patients were attending a referral clinic, where more emphasis was possibly placed on adherence. In addition, there is evidence that women are more likely to be aware of hypertension ${ }^{16}$ and to make better use of healthcare services than men, ${ }^{17}$ which could increase their motivation to adhere to antihypertensive treatment, even though a recent meta-analysis did not find definitive evidence for this. ${ }^{18}$ Interestingly, high therapeutic adherence did not relate to BP control in our 
study. This finding may suggest that a significant number of patients were truly resistant to treatment.

In our sample, as in other studies, ${ }^{19}$ there was a high prevalence of depression (23\%) among women with hypertension. Comorbid major depression is three times more common in psychiatric outpatients with hypertension than in those without hypertension, an aspect that may be aggravated by sex differences, since depression is twice as prevalent in women as in men. ${ }^{20,21}$ Furthermore, depressive symptoms may be related to a decline in medication adherence among hypertensive patients, a finding also observed in our study and consistent with the literature. ${ }^{22,23}$ In fact, depressive symptoms are associated with reduced functioning and may also mediate the patient's self-perception of performing a specific activity (expectation of selfefficacy), leading the individual to make less effort to follow the prescribed recommendations and amplifying possible obstacles to medication adherence. ${ }^{23,24}$ In addition, in a previous study involving patients with depressive disorder and low social support, women of African descent (which in our sample represented almost $95 \%$ of the patients) were less likely to adhere to depression treatment when compared to white males and females. ${ }^{25}$ This finding may possibly indicate a low therapeutic adherence for other clinical comorbidities, such as hypertension.

In this regard, due to the high prevalence of comorbid depression in hypertension and its clinical implications for therapeutic adherence, it is important to reinforce the importance of recognition and screening of mood disorders in hypertensive patients, especially in women of African descent.

Regarding drug therapy regimens, we found that diuretics were the most commonly prescribed medications, followed by ARB and CCB. These results corroborate the findings of a previous meta-analysis, which observed that women more frequently used diuretics for treatment of hypertension, whereas men more often used beta-blockers, ACEI, and CCB. ${ }^{26} \mathrm{~A}$ possible explanation for the preference of diuretics may be the side effects of some hypertensive medications, which affect women more often than men. Indeed, women experience a higher frequency of dry cough when taking ACEI, in addition to a higher incidence of edema and vasodilatation symptoms with CCB compared to men. ${ }^{27,28}$ Despite these differences in therapeutic profile between genders, there is no evidence that blood pressure-lowering regimens (based on ACEI, CCB, ARB, or diuretics/beta-blockers) provide different levels of protection against major cardiovascular events in men and women. ${ }^{29}$

As recommended in the literature, ${ }^{8}$ we observed that a large proportion of patients with apparent $\mathrm{RH}$ used the combination of a thiazide diuretic, a long-acting CCB, and a renin-angiotensin system blocker, which is the preferable regimen for resistant hypertension. Moreover, the addition of spironolactone was observed in most patients who needed four or more antihypertensive drugs. This represents a significant increase in the number of spironolactone prescriptions compared to previous studies, ${ }^{30}$ probably reflecting the increasing recognition of its efficacy in $\mathrm{RH}$ as documented by several reports, particularly the PATHWAY-2 trial. ${ }^{31}$ Nevertheless, the most common addition to the triple $\mathrm{ACEI} / \mathrm{ARB}+$ diuretic + CCB regimen was a beta-blocker (63.6\%), which could be justified by the high prevalence of CAD, previous MI, and HF in these patients.

On the other hand, only one-fourth of the women were on chlortalidone, despite recommendations in the literature supporting its use, especially in RH. ${ }^{32}$ This is probably due to the fact that the study was conducted at a public clinic and chlortalidone is not covered by the Brazilian public health system. This also raises concerns about the prevalence of refractory hypertension, given the current definition of this phenotype, which requires the inclusion of spironolactone and a long-acting thiazide-like diuretic, such as chlorthalidone, in the therapeutic regimen. ${ }^{8,33}$ Among the 24 patients with uncontrolled blood pressure despite the use of 5 or more antihypertensive drugs, only 11 (45.8\%) were receiving the combination of spironolactone and chlorthalidone and could possibly meet the criteria for refractory hypertension. Future studies will need to clarify how the prevalence of refractory hypertension changes with the implementation of diuretic optimization in a higher proportion of patients.

Our study has some limitations. First, its crosssectional design precludes causal inference between the associations found. Second, we used the MMAS- 8 questionnaire to assess therapeutic adherence, which, despite being widely used, has limited accuracy in detecting nonadherence. ${ }^{34}$ Third, we could not exclude the white-coat effect as a cause of pseudo-resistance in some patients. However, these patients were followed at a specialized hypertension clinic with a mean followup greater than 10 years, which could minimize the prevalence of pseudo-resistance in this population. 
Another point is that, despite current recommendations for BP measurement, ${ }^{8}$ we did not use the average of two measurements obtained in the arm with the highest BP levels as the reference value for the patient's BP. Instead, two measurements were performed, one in each arm, and the measurement with the highest mean arterial pressure was considered for analysis. Finally, the assessment of depression was based exclusively on patient self-report, with no specific instrument being applied for the diagnosis or measurement of the intensity of depressive symptoms.

Despite these limitations, our study also has strengths. To our knowledge, few studies were conducted with the aim of evaluating the clinical and therapeutic profile of hypertension exclusively in women in Brazil. Finally, the present study involved a sample of predominantly African descent, thus contributing to improved knowledge of the presentation and management of hypertension in this population.

\section{Conclusions}

In conclusion, in a sample of women with hypertension, we found a high prevalence of comorbid cardiovascular risk factors and previous cardiovascular events. Stroke was more often found in women with uncontrolled blood pressure levels, even though these patients were on more antihypertensive drugs, and self-reported depression was significantly associated with nonadherence. The therapeutic profile revealed that most patients were on three or more antihypertensive drugs; however, very few of them were taking a long-acting thiazide-like diuretic for resistant hypertension. Taken together, our findings reinforce the importance of conducting studies exclusively with women with hypertension in order to

\section{References}

1. Appelman $Y$, van Rijn BB, Ten Haaf ME, Boersma E, Peters SA. Sex differences in cardiovascular risk factors and disease prevention. Atherosclerosis. 2015;241(1):211-8. doi: 10.1016/j. atherosclerosis.2015.01.027.

2. Millett ERC, Peters SAE, Woodward M. Sex differences in risk factors for myocardial infarction: cohort study of UK Biobank participants. BMJ. 2018;363:k4247. doi: 10.1136/bmj.k4247.

3. Peters SA, Huxley RR, Woodward M. Diabetes as a risk factor for stroke in women compared with men: a systematic review and meta-analysis of 64 cohorts, including 775,385 individuals and 12,539 strokes. Lancet. 2014;383(9933):1973-80. doi: 10.1016/S0140-6736(14)60040-4.

4. Li X, Li X, Lin H, Fu X, Lin W, Li M, et al. Metabolic syndrome and stroke: a meta-analysis of prospective cohort studies. J Clin Neurosci. 2017;40:34-8. doi: 10.1016/j.jocn.2017.01.018. improve treatment adherence, blood pressure control, and clinical outcomes in this specific population.

\section{Potential Conflict of Interest}

No potential conflict of interest relevant to this article was reported.

\section{Sources of Funding}

There were no external funding sources for this study.

\section{Study Association}

This study is not associated with any thesis or dissertation work.

\section{Ethics approval and consent to participate}

This study was approved by the Ethics Committee of the Hospital Universitário Professor Edgard Santos under the protocol number 81701717.6.0000.0049. All the procedures in this study were in accordance with the 1975 Helsinki Declaration, updated in 2013. Informed consent was obtained from all participants included in the study.

\section{Author contributions}

Conception and design of the research: Macedo CRB, Aras-Jr R. Acquisition of data: Barletta PHAAS, Magalhães EFS, Almeida VF, Moreira JL, Silva MJ. Analysis and interpretation of the data: Barletta PHAAS, Magalhães EFS, Almeida VF. Statistical analysis: Barletta PHAAS, Almeida VF. Writing of the manuscript: Barletta PHAAS, Magalhães EFS, Almeida VF, Moreira JL, Silva MJ. Critical revision of the manuscript for intellectual content: Barletta PHAAS, Magalhães EFS, Almeida VF, Moreira JL, Silva MJ, Macedo CRB, Aras-Jr R.

5. Masjedi S, Ferdous Z. Understanding the role of sex in heart valve and major vascular diseases. Cardiovasc Eng Technol. 2015;6(3):209-19. doi: 10.1007/s13239-015-0226-x.

6. Smith SM, Huo T, Johnson BD, Bittner V, Kelsey SF, Thompson DV, et al. Cardiovascular and mortality risk of apparent resistant hypertension in women with suspected myocardial ischemia: a report from the NHLBIsponsored WISE study. J Am Heart Assoc. 2014;3(1):e000660. doi: 10.1161/ JAHA.113.000660.

7. Adigun RO, Boler AN, Mankad R. Disparities in cardiac care of women: current data and possible solutions. Curr Treat Options Cardiovasc Med. 2018;20(11):87. doi: 10.1007/s11936-018-0688-x.

8. Barroso WKS, Rodrigues CIS, Bortolotto LA, Mota-Gomes MA, Brandão AA, Feitosa ADM, et al. Brazilian Guidelines of Hypertension - 2020. Arq Bras Cardiol. 2021;116(3):516-658. doi: 10.36660/abc.20201238. 
9. Levey AS, Stevens LA, Schmid CH, Zhang YL, Castro AF 3rd, Feldman $\mathrm{HI}$, et al. A new equation to estimate glomerular filtration rate. Ann Intern Med. 2009;150(9):604-12. doi: 10.7326/0003-4819-150-9-200905050-00006.

10. Chedier B, Cortez AF, Roderjan CN, Cavalcanti AH, Carlos FOC, Santos $\mathrm{BDM}$, et al. Prevalence and clinical profile of refractory hypertension in a large cohort of patients with resistant hypertension. J Hum Hypertens. 2020. doi: 10.1038/s41371-020-00406-2.

11. Tziomalos K, Giampatzis V, Baltatzi M, Efthymiou E, Psianou K, Papastergiou N, et al. Sex-specific differences in cardiovascular risk factors and blood pressure control in hypertensive patients. J Clin Hypertens. 2014;16(4):309-12. doi: 10.1111/jch.12289.

12. Silva PM, Lima MJ, Neves PM, Macedo ME. Prevalence of cardiovascular risk factors and other comorbidities in patients with hypertension in Portuguese primary health care populations: The PRECISE study. Rev Port Cardiol. 2019;38(6):427-37. doi: 10.1016/j.repc.2018.09.011.

13. Oparil S, Acelajado MC, Bakris GL, Berlowitz DR, Cífková R, Dominiczak AF, et al. Hypertension. Nat Rev Dis Primers. 2018;4:18014. doi: 10.1038/ nrdp.2018.14.

14. Oliveira-Filho AD, Barreto-Filho JA, Neves SJ, Lyra DP Jr. Association between the 8-item Morisky Medication Adherence Scale (MMAS-8) and blood pressure control. Arq Bras Cardiol. 2012;99(1):649-58. doi: 10.1590/ s0066-782x2012005000053.

15. Morisky DE, Ang A, Krousel-Wood M, Ward HJ. Predictive validity of a medication adherence measure in an outpatient setting. J Clin Hypertens. 2008;10(5):348-54. doi: 10.1111/j.1751-7176.2008.07572.x.

16. Chor D, Ribeiro ALP, Carvalho MS, Duncan BB, Lotufo PA, Nobre AA, et al. Prevalence, awareness, treatment and influence of socioeconomic variables on control of high blood pressure: results of the ELSA-Brasil study. PLoS One. 2015;10(6):e0127382. doi: 10.1371/journal.pone.0127382.

17. Hong SH. Potential for physician communication to build favorable medication beliefs among older adults with hypertension: A crosssectional survey. PLoS One. 2019;14(1):e0210169. doi: 10.1371/journal. pone.0210169.

18. Biffi A, Rea F, Iannaccone T, Filippelli A, Mancia G, Corrao G. Sex differences in the adherence of antihypertensive drugs: a systematic review with meta-analyses. BMJ Open. 2020;10(7):e036418. doi: 10.1136/ bmjopen-2019-036418.

19. Li Z, Li Y, Chen L, Chen P, Hu Y. Prevalence of depression in patients with hypertension: a systematic review and meta-analysis. Medicine. 2015;94(31):e1317. doi: 10.1097/MD.0000000000001317.

20. Rabkin JG, Charles E, Kass F. Hypertension and DSM-III depression in psychiatric outpatients. Am J Psychiatry. 1983;140(8):1072-4. doi: 10.1176/ ajp.140.8.1072.

21. Mauvais-Jarvis F, Merz NB, Barnes PJ, Brinton RD, Carrero JJ, DeMeo DL, et al. Sex and gender: modifiers of health, disease, and medicine. Lancet. 2020;396(10250):565-82. doi: 10.1016/S0140-6736(20)31561-0.

22. Krousel-Wood M, Joyce C, Holt E, Muntner P, Webber LS, Morisky DE, et al. Predictors of decline in medication adherence: results from the cohort study of medication adherence among older adults. Hypertension. 2011;58(5):804-10. doi: 10.1161/HYPERTENSIONAHA.111.176859.

23. Bautista LE, Vera-Cala LM, Colombo C, Smith P. Symptoms of depression and anxiety and adherence to antihypertensive medication. Am J Hypertens. 2012;25(4):505-11. doi: 10.1038/ajh.2011.256.

24. Son YJ, Won MH. Depression and medication adherence among older Korean patients with hypertension: mediating role of self-efficacy. Int J Nurs Pract. 2017;23(3). doi: 10.1111/ijn.12525.

25. Gerlach LB, Kavanagh J, Watkins D, Chiang C, Kim HM, Kales HC With a little help from my friends?: racial and gender differences in the role of social support in later-life depression medication adherence. Int Psychogeriatr. 2017;29(9):1485-93. doi: 10.1017/S104161021700076X

26. Klungel $\mathrm{OH}$, de Boer A, Paes AH, Seidell JC, Bakker A. Sex differences in the pharmacological treatment of hypertension: a review of populationbased studies. J Hypertens. 1997;15(6):591-600. doi: 10.1097/00004872199715060-00004.

27. Muiesan ML, Salvetti M, Rosei CA, Paini A. Gender differences in antihypertensive treatment: myths or legends? High Blood Press Cardiovasc Prev. 2016;23(2):105-13. doi: 10.1007/s40292-016-0148-1.

28. Song JJ, Ma Z, Wang J, Chen LX, Zhong JC. Gender differences in hypertension. J Cardiovasc Transl Res. 2020;13(1):47-54. doi: 10.1007/ s12265-019-09888-z.

29. Turnbull F, Woodward M, Neal B, Barzi F, Ninomiya T, Chalmers J, et al. Do men and women respond differently to blood pressure-lowering treatment? Results of prospectively designed overviews of randomized trials. Eur Heart J. 2008;29(21):2669-80. doi: 10.1093/eurheartj/ehn427.

30. Hwang AY, Dave C, Smith SM. Trends in antihypertensive medication use among US patients with resistant hypertension, 2008 to 2014. Hypertension. 2016;68(6):1349-54. doi: 10.1161/HYPERTENSIONAHA.116.08128.

31. Williams B, MacDonald TM, Morant S, Webb DJ, Sever P, McInnes G, et al. Spironolactone versus placebo, bisoprolol, and doxazosin to determine the optimal treatment for drug-resistant hypertension (PATHWAY-2): a randomised, double-blind, crossover trial. Lancet. 2015;386(10008):205968. doi: 10.1016/S0140-6736(15)00257-3.

32. Acelajado MC, Hughes ZH, Oparil S, Calhoun DA. Treatment of resistant and refractory hypertension. Circ Res. 2019;124(7):1061-70. doi: 10.1161/ CIRCRESAHA.118.312156.

33. Whelton PK, Carey RM, Aronow WS, Casey DE Jr, Collins KJ, Himmelfarb CD, et al. 2017 ACC/AHA/AAPA/ABC/ACPM/AGS/ $\mathrm{APhA} / \mathrm{ASH} / \mathrm{ASPC} / \mathrm{NMA} / \mathrm{PCNA}$ Guideline for the prevention, detection, evaluation, and management of high blood pressure in adults: a report of the American College of Cardiology/American Heart Association task force on clinical practice guidelines. Hypertension. 2018;71(6):13-115. doi: 10.1161/HYP.0000000000000065.

34. Pandey A, Raza F, Velasco A, Brinker S, Ayers C, Das SR, et al. Comparison of Morisky Medication Adherence Scale with therapeutic drug monitoring in apparent treatment-resistant hypertension. J Am Soc Hypertens. 2015;9(6):420-6.e2. doi: 10.1016/j.jash.2015.04.004. 